\title{
Management quality indicators and in- hospital mortality among acute coronary syndrome patients admitted to tertiary hospitals in Ethiopia: prospective observational study
}

Korinan Fanta ${ }^{1 *}$, Fekede Bekele Daba ${ }^{1}$, Elsah Tegene ${ }^{2}$, Tsegaye Melaku', Ginenus Fekadu ${ }^{3,4}$ and Legese Chelkeba ${ }^{5}$

\begin{abstract}
Background: Acute coronary syndrome (ACS) remains the leading cause of cardiovascular disease mortality and morbidity worldwide. While the management quality measures and clinical outcomes of patients with ACS have been evaluated widely in developed countries, inadequate data are available from sub-Saharan Africa countries. So, this study aimed to assess the clinical profiles, management quality indicators, and in-hospital outcomes of patients with ACS in Ethiopia.
\end{abstract}

Methods: A Prospective observational study was conducted at two tertiary hospitals in Ethiopia from March 2018 to November 2018. The primary outcome of the study was in-hospital mortality. Data were analyzed using SPSS version 23.0. Multivariable cox-regression was conducted to identify predictors of time to in-hospital mortality. Variable with $p$-value $<0.05$ was considered statistically significant.

Results: Among 181 ACS patients enrolled, about (61\%) were presented with ST-elevation myocardial infarction (STEMI). The mean age of the study participant was $55.8 \pm 11.9$ years and $62.4 \%$ were males. The use of guidelinedirected medications within $24 \mathrm{~h}$ of hospitalization were sub-optimal (57\%) [Dual antiplatelet (73\%), statin (74\%), beta-blocker (67\%) and ACEI (61\%)]. Only (7\%) ACS patients received the percutaneous coronary intervention (PCI). Discharge aspirin and statin were high (>90\%) while other medications were sub-optimal $(<80 \%)$. The all-cause inhospital mortality rate was $20.4 \%$ and the non-fatal MACE rate was $25 \%$. Rural residence (AHR: $3.64,95 \%$ Cl: $1.81-$ 7.29), symptom onset to hospital arrival > 12 h (AHR: 4.23, 95\% Cl: 1.28-13.81), and Cardiogenic shock (AHR: 7.20, 95\% Cl: 3.55-14.55) were independent predictors of time to in-hospital death among ACS patients.

\footnotetext{
*Correspondence: korif53@gmail.com

1 Department of Clinical Pharmacy, Institute of Health, Jimma University, P.O.Box: 378, Jimma, Oromia, Ethiopia

Full list of author information is available at the end of the article
}

(c) The Author(s). 2021 Open Access This article is licensed under a Creative Commons Attribution 4.0 International License, which permits use, sharing, adaptation, distribution and reproduction in any medium or format, as long as you give appropriate credit to the original author(s) and the source, provide a link to the Creative Commons licence, and indicate if changes were made. The images or other third party material in this article are included in the article's Creative Commons licence, unless indicated otherwise in a credit line to the material. If material is not included in the article's Creative Commons licence and your intended use is not permitted by statutory regulation or exceeds the permitted use, you will need to obtain permission directly from the copyright holder. To view a copy of this licence, visit http://creativecommons.org/licenses/by/4.0/. The Creative Commons Public Domain Dedication waiver (http://creativecommons.org/publicdomain/zero/1.0/) applies to the data made available in this article, unless otherwise stated in a credit line to the data. 
(Continued from previous page)

Conclusion: In the present study, the use of guideline-directed in-hospital medications was sub-optimal.

The overall in-hospital mortality rate was unacceptably high and highlights the urgent need for national qualityimprovement focusing on timely initiation of evidence-based medications, reperfusion therapy, and strategies to reduce pre-hospital delay.

Keywords: Acute coronary syndrome, Myocardial infarction, Management quality indicators, Mortality, Sub-Saharan Africa

\section{Introduction}

Ischemic heart disease (IHD) remains the leading cause of cardiovascular disease mortality and morbidity worldwide [1]. The mortality rate from IHD is slowly trending down in most high-income countries with advancements in the acute management of acute coronary syndromes (ACS) such as coronary revascularization, primary and secondary preventive measures after myocardial infarction and better treatment of IHD risk factors [2, 3]. However, IHD mortality rate in low and middle-income countries (LMICs) are sharply increasing as a result of an increase in cardiovascular risk factors and globalization $[4,5]$.

ACS is a forgotten domain in sub-Saharan Africa (SSA) since it was historically believed to be uncommon [6]. However, in recent years, SSA has faced a rapid increase in IHD risk factors, including hypertension, diabetes, dyslipidemia, obesity, and physical inactivity augmented by rapid urbanization and globalization [7]. On top of such demographic and epidemiologic transition, SSA countries have few interventional cardiology facilities equipped with cardiac catheterization laboratories $[8,9]$ Indeed, access to a pre-hospital emergency medical service and reperfusion therapy such as percutaneous coronary intervention and thrombolytic medications are very limited in this area $[9,10]$ As a result of these challenges, it is difficult to apply evidence-based Western guidelines on ACS management in most SSA countries.

While performance quality measures and clinical outcomes of patients with ACS have been evaluated widely in Western countries, inadequate data are available from SSA [11]. Indeed, the available fewer studies were limited to retrospective chart review with a small sample size, except the ACCESS-south Africa sub-analysis which prospectively enrolled large populations [12]. As a result, cardiovascular society in SSA advocate for the establishment of a prospective ACS register in SSA to increase awareness on the disease burden and strategies to optimize management protocol and clinical outcomes of ACS in the region [9].

Ethiopia, the second-most populous country in Africa (over 100 million people), is facing an increase in cardiovascular disease (CVD) burden [13]. According to the 2015 global burden of disease study, IHD is one of the top five leading causes of premature mortality in the country [14]. Despite the increasing burden of CVD in Ethiopia, the country suffers from a severe shortage of cardiologists (almost one digit) and has a few modern cardiac catheterization laboratories [15]. Facing these shortcomings, a little is known about the burden, management strategy, and clinical outcomes of ACS in the country. Therefore, this study aimed to assess the clinical profile, management quality indicators and clinical outcomes of patients with ACS admitted to two tertiary hospitals in Ethiopia.

\section{Methods}

\section{Study design and clinical setting}

A prospective observational study was conducted at two tertiary hospitals in Ethiopia including Jimma University Medical Center (JUMC) and Saint Peter's Specialized Hospital (SPSH). JUMC serves as a referral center for the southwestern part of the country (over 15,000,000 catchment population). JUMC provides general internal medicine, cardiology, and other specialty services. SPSH is in Addis Ababa and it is one of a few public hospitals which provide cardiac catheterization laboratories in Ethiopia. The study was carried out from March 15 to November 15, 2018.

\section{Study population}

All consecutive ACS patients admitted to JUMC and SPSH fulfilling the inclusion criteria were included. Patients were included if they fulfilled the following inclusion criteria: (I) age $\geq 18$ years; (II) willing to provide written or oral informed consent; and (III) confirmed diagnosis of ACS based on the Third Universal Definition of Myocardial Infarction [16]. Patients who died before assessment, readmitted patients, change to the initial ACS diagnoses, and patients with non-type I myocardial infraction (secondary to non-ACS etiology) were excluded from the study. In this study, patients were categorized based on ACS subtype into ST-elevation myocardial infarction (STEMI) or non-ST-elevation acute coronary syndromes [NSTE-ACS: includes unstable angina (UA) or non-ST-elevation myocardial infarction (NSTEMI)] [17, 18]. 


\section{Data collection}

Using a pre-tested structured questioner, two trained nurses and two medical interns collected clinical data by interviewing hospitalized patients and extracting relevant data from patient's medical records. The data collection tool includes sociodemographic characteristics, key diagnostics investigations (electrocardiography, cardiac biomarkers, echocardiography, and angiography), management (guideline-directed medications within the first $24 \mathrm{~h}$ of hospital admission and at discharge), and inhospital clinical outcomes [in-hospital mortality and nonfatal major adverse cardiovascular events (MACE)].

Guideline-directed in-hospital medications were defined as the initiation of dual antiplatelet (Aspirin + one P2 $\mathrm{Y}_{12}$ inhibitor), beta blocker, and angiotensin converting enzyme (ACE) inhibitor within $24 \mathrm{~h}$ of hospitalization. Guideline-directed discharge medications were defined as receiving dual antiplatelet therapy (aspirin + one P2Y12 inhibitor), beta-blockers, statin, and ACE inhibitor at discharge. Guideline-directed medications were evaluated as quality of care indicators based on the international guideline for the management of STEMI or NSTE-ACS adopted at respective hospitals $[17,18]$.

\section{Study outcomes and validating tools}

The primary outcome of the study was in-hospital mortality which was ascertained from treating physician death summary note. The secondary endpoint was new onset non-fatal MACE defined as a composite of heart failure, stroke, re-infarction, cardiogenic shock, and major bleeding during a hospital stay. Definition for various components of MACE was available in the supplementary material (Clinical Check-list). All clinical endpoints were recorded by following patients on daily basis from admission to discharge or death.

\section{Ethical approval and consent to participate}

The study protocol was approved by the Institutional Review Board (IRB) of Jimma University, Institute of Health with a reference number of IHRPGD/193/18. Permission was obtained from responsible bodies of respective hospitals before interviewing patients and extracting data from active patient's case records. Written and verbal informed consent was obtained from all study participants.

\section{Statistical analysis}

The collected data were checked for completeness, clarity, and accuracy. Data was entered into Epidata version 4.2 and analyzed using statistical package for social science (SPSS) version 23 (IBM, Armonk, NY, USA). Patient characteristics, management, and clinical outcomes were summarized according to ACS subtypes. Continuous variables were presented as mean \pm standard deviation or median (interquartile range), and categorical variables are presented as frequency (\%). In-hospital ACS mortality rate was compared using Kaplan-Meier and $\log$ rank test. $P$-value $<0.25$ was considered as a cut-off point to select variables on binary regression for multivariable Cox regression to determine independent predictors of time to ACS mortality. Two-tailed $p$ -value $<0.05$ was considered statistically significant.

\section{Results}

Among 203 patients presented with ACS during the study period, 181 patients with a confirmed diagnosis of ACS were included. Of the181 patients enrolled, 111 (61.3\%) patients had STEMI and 70 (38.7\%) patients had NSTE-ACS.

\section{Sociodemographic characteristics}

The mean age of the study participants was $55.8 \pm 11.9$ years and $62.4 \%$ were males. About three -fourths (75.7\%) were urban or semi-urban residents while more than half of the patients had no formal education. Only 9.4\% of the study participants were transported to the hospital by ambulance. The median (IQR) time from symptom onset to first medical contact was 26 (10-43) hours without significant difference (Table 1).

\section{Key diagnostics and in-hospital management of ACS}

The majority of the patients (79.6\%) received an ECG within the first $24 \mathrm{~h}$ of hospital arrival and all patients received an ECG at some point during their hospital stay. Cardiac biomarkers were measured for all patients during hospitalization and $72.4 \%$ had elevated troponin I level. Diagnostic angiography was available at SPSH and it was performed for $43.6 \%$ of patients. Transthoracic Doppler echocardiography was done for 96.1 and 38.7\% of the patients had reduced left ventricular ejection fraction (LVEF) less than 40\% (Table 2).

Dual antiplatelet therapy (aspirin + clopidogrel) was administered for $73 \%$ of the patients during the first $24 \mathrm{~h}$ of hospital admission. The use of other guidelinedirected medications includes statin $(74.6 \%)$, betablockers (67.2\%), any heparin (61.3), and ACEI/ARB (61.3) within the first $24 \mathrm{~h}$ of hospital admission. Patients presented with STEMI were more likely to receive evidence-based medication within the first $24 \mathrm{~h}$ of hospitalization compared to those presented with NSTEACS (Table 2).

None of the study participants received thrombolytic medications during hospitalization due to the unavailability of the medications. Although $43.6 \%$ of the participant undergone diagnostic cardiac catheterization, only 13 (7.2\%) of the patients received percutaneous coronary interventions $(\mathrm{PCI})$ during hospitalization. 
Table 1 Baseline characteristics of ACS patients admitted to selected tertiary hospitals in Ethiopia based on ACS subtypes

\begin{tabular}{|c|c|c|c|c|c|}
\hline Patient Characteristics & & All patients $(n=181)$ & STEMI $(n=111)$ & NSTE-ACS $(n=70)$ & $P$-value \\
\hline Age (years) & Mean \pm SD & $55.8 \pm 11.9$ & $55.2 \pm 11.4$ & $56.9 \pm 12.7$ & 0.349 \\
\hline \multirow[t]{2}{*}{ Sex } & Male & $113(62.4 \%)$ & $70(63.1)$ & $43(61.4)$ & 0.825 \\
\hline & Female & $68(37.6)$ & $41(36.9)$ & 27 (38.6) & \\
\hline \multirow[t]{2}{*}{ Residence } & Urban/semi-urban & $137(75.7)$ & 85 (76.6) & $52(74.3)$ & 0.726 \\
\hline & Rural & $44(24)$. & $26(23.4)$ & $18(25.7)$ & \\
\hline \multirow[t]{4}{*}{ Educational status } & Illiterate & $57(31.5)$ & $35(31.5)$ & $22(51.4)$ & 0.290 \\
\hline & Read and write & $42(23.2)$ & $25(22.5)$ & $17(24.3)$ & \\
\hline & Primary school & $29(16.0)$ & $14(12.6)$ & $15(21.4)$ & \\
\hline & Secondary and above & $53(29.3)$ & $37(33.3)$ & $16(22.9)$ & \\
\hline \multirow[t]{4}{*}{ Occupational status } & Employed & $43(23.8)$ & $24(21.6)$ & $19(27.1)$ & 0.526 \\
\hline & Merchant & $55(30.4)$ & 37 (33.3) & $18(25.7)$ & \\
\hline & Farmer/labor workers & $30(16.6)$ & $20(18.0)$ & $10(14.3)$ & \\
\hline & Unemployed/retired & $53(29.3)$ & $30(27.0)$ & $23(32.9)$ & \\
\hline \multirow[t]{2}{*}{ Type of transportation } & Ambulance & $17(9.4)$ & $13(11.7)$ & $4(5.7)$ & 0.178 \\
\hline & Taxi/public bus & $164(90.6)$ & $98(88.3)$ & $66(94.3)$ & \\
\hline \multirow[t]{3}{*}{ Symptom onset to hospital arrival } & median (IQR) & $26(10-43)$ & $26(8-48)$ & $26.5(12-40)$ & 0.925 \\
\hline & $\leq 12 \mathrm{~h}$ & $59(32.6)$ & $40(36.0)$ & $19(27.1)$ & 0.214 \\
\hline & $>12 \mathrm{~h}$ & $122(67.4)$ & $71(64.0)$ & $51(72.9)$ & \\
\hline
\end{tabular}

IQR Interquartile range, NSTE-ACS Non-ST-elevation acute coronary syndrome, STEMI ST-elevation Myocardial Infarction, SD Standard deviation

\section{In-hospital complications of ACS}

The overall all in-hospital mortality rate was $20.4 \%$ with significant difference between STEMI (26\%) and NSTEACS (11.4\%) [ $p=0.017]$. The rate of non-fatal MACE defined as cardiogenic shock, stroke, re-infarction, and major bleeding during hospitalization was 25\% (STEMI $28 \%$ and NSTEMI 20\%). Cardiogenic shock was statistically significant among patients presented with STEMI compared to NSTE-ACS patients $(p=0.043)$. There was no statistically significant difference in other non-fatal MACE among ACS subtypes. Other common complications recorded during hospitalization were acute kidney injury (12.2\%), hospital acquired infections (8.8\%) and atrial fibrillations (7.2\%) (Table 2).

\section{Discharge medications}

Focusing on guideline-directed discharge medications, we have evaluated prescriptions of key medications on discharge. Discharge dual antiplatelet therapy was 76\% (97\% for aspirin alone). Statin prescription at discharge was high (96\%), followed by beta-blockers (83\%) and ACEI/ ARB (76\%). Discharge prescriptions of aspirin and clopidogrel were more common among STEMI patients compared to NSTEM-ACS patients with statistical significance $(p=0.020$ and $p=0.007)$, respectively (Table 3$)$.

\section{Predictors of time to in-hospital mortality}

On multivariable Cox-regression analysis, rural residence, symptom onset to FMC $>12 \mathrm{~h}$, and Cardiogenic shock complication were independent predicators of time to in-hospital death among ACS patients. The inhospital mortality rate was 3.64 times higher in ACS patients from rural areas compared to those from urban areas [Adjusted hazard ratio (AHR): 3.64, 95\% CI: 1.817.29). Similarly, the rate of in-hospital mortality in patients presented to the hospitals after $12 \mathrm{~h}$ of symptom onset was 4.23 times more than patients presented to hospital within $12 \mathrm{~h}$ of symptom onset (AHR: 4.23, 95\% CI: 1.28-13.81). In addition, the risk of in-hospital mortality in patients who develop cardiogenic shock was 7.20 times more than those patients without cardiogenic shock (AHR: 7.20, 95\% CI: 3.55-14.55). (Table 4). Survival probability curve were generated from Kaplan Meier in-hospital death for independent predictors and compared by Log rank (Fig. 1).

\section{Discussion}

Through this prospective observational study, we evaluated the process of care as quality indicators and recorded a range of in-hospital events among ACS patients admitted to two tertiary hospitals in Ethiopia. Most of our study participants were presented with STEMI in their mid-50s, with male predominance.

Prolonged pre-hospital delay (median 26h) was recorded in our study participants which is excessively longer than the average time reported by other observational studies from low and middle income countries [19-21]. This prolonged pre-hospital delay in 
Table 2 key diagnostics and evidence-based medications within the first $24 \mathrm{~h}$ and in-hospital outcomes based on ACS subtypes

\begin{tabular}{|c|c|c|c|c|c|}
\hline Diagnostics and Medications & & $\begin{array}{l}\text { All patients } \\
n=181\end{array}$ & $\begin{array}{l}\text { STEMI } \\
n=111\end{array}$ & NSTE-ACS $n=70$ & $P$ value \\
\hline \multirow[t]{5}{*}{ Key diagnostics } & ECG within $12 \mathrm{~h}$ & $154(79.6)$ & $90(81.1)$ & $54(77.1)$ & 0.522 \\
\hline & Positive cardiac biomarker & $161(89.0)$ & $111(100.0)$ & $50(71.4)$ & $<0.001^{*}$ \\
\hline & Diagnostic Angiography & 79 (43.6) & $52(46.8)$ & 27 (38.6) & 0.274 \\
\hline & Echocardiography & $174(96.1)$ & $107(96.4)$ & $64(95.7)$ & 0.817 \\
\hline & LVEF $<40 \%$ & $70(38.7)$ & $42(37.8)$ & $28(40.0)$ & 0.771 \\
\hline \multirow[t]{8}{*}{ In-hospital medications within $24 \mathrm{~h}$} & Aspirin & $140(77.3)$ & $92(82.8)$ & $48(68.6)$ & $0.025^{*}$ \\
\hline & Clopidogrel & $132(72.9)$ & $88(79.3)$ & $44(62.8)$ & $0.015^{*}$ \\
\hline & Dual antiplatelet & $132(72.9)$ & $88(79.3)$ & $44(62.8)$ & $0.015^{*}$ \\
\hline & Beta-blocker $(n=147)$ & $141(67.2)$ & $80(72.7)$ & $41(58.6)$ & $0.023^{*}$ \\
\hline & Any heparin & $111(61.3)$ & $73(65.8)$ & $38(54.3)$ & 0.122 \\
\hline & Statin & $135(74.6)$ & $90(81.1)$ & $45(64.3)$ & $0.011^{*}$ \\
\hline & ACEI/ARBs $(n=132)$ & $111(61.3)$ & $73(65.8)$ & $38(54.3)$ & 0.449 \\
\hline & All GDMT ${ }^{\mathrm{a}}$ & $103(56.9)$ & $71(64.0)$ & $32(45.7)$ & 0.016 \\
\hline \multirow[t]{2}{*}{ In-hospital reperfusion therapy } & Thrombolysis n (\%) & $0(0)$ & $0(0)$ & $0(0)$ & - \\
\hline & $\mathrm{PCl}$ n (\%) & $13(7.2)$ & $10(9)$ & $3(3.4)$ & 0.231 \\
\hline \multirow[t]{10}{*}{ In-hospital events } & Mortality & $37(20.4)$ & $29(26.1)$ & $8(11.4)$ & 0.017 \\
\hline & Cardiogenic shock & $16(8.8)$ & $13(11.7)$ & $3(4.3)$ & $0.043^{*}$ \\
\hline & Stroke & $5(2.8)$ & $3(2.7)$ & $2(2.9)$ & 0.951 \\
\hline & Re-infraction & $10(5.5)$ & $7(6.3)$ & $3(4.3)$ & 0.562 \\
\hline & Major bleeding & $7(3.9)$ & $4(3.6)$ & $3(4.3)$ & 0.818 \\
\hline & Heart failure & $18(10.0)$ & $13(11.7)$ & $5(7.0)$ & 0.317 \\
\hline & Non-fatal MACE & $45(25.0)$ & $31(28.0)$ & $14(20.0)$ & 0.299 \\
\hline & Acute kidney injury & $22(12.2)$ & $13(11.7)$ & $9(12.9)$ & 0.818 \\
\hline & Atrial fibrillation & $13(7.2)$ & $7(6.3)$ & $6(8.6)$ & 0.565 \\
\hline & Hospital acquired infection & $16(8.8)$ & $10(9.0)$ & $6(8.6)$ & 0.920 \\
\hline
\end{tabular}

ACEI Angiotensin-converting enzyme inhibitor, ARB Angiotensin-receptor blockers, ECG Electrocardiography, GDMT Guideline-directed medical therapy, LVEF Left ventricular ejection fraction, MACE Major adverse cardiovascular events, NSTE-ACS Non-ST-elevation acute coronary syndrome, PCI Percutaneous coronary intervention, STEMI ST-elevation myocardial infarction

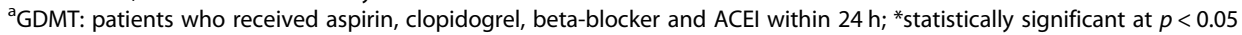

our study participants were mostly due to limited access to emergency medical service (only $13 \%$ used ambulance), long distance travel (especially rural residents), lack of awareness of ACS symptoms importance (more than half had no formal education), and economic reasons.
The use of guideline-directed in-hospital medications such as aspirin, clopidogrel, statin, beta-blockers, and ACEIs/ARB within the first $24 \mathrm{~h}$ in our study was low compared to other studies from LMICs [12, 19, 22, 23]. This might be explained by significant difference in patient level socio-economic status and lack of standard

Table 3 Discharge medications according to ACS subtypes

\begin{tabular}{lllll}
\hline Discharge medications & All patients $(\boldsymbol{n}=\mathbf{1 4 4})$ & STEMI $(\boldsymbol{n}=\mathbf{8 2})$ & NSTE-ACS $(\boldsymbol{n}=\mathbf{6 2})$ & $\boldsymbol{p}$-value \\
\hline Aspirin & $140(97.2)$ & $82(100.0)$ & $58(93.5)$ & 0.020 \\
Clopidogrel & $109(75.7)$ & $69(84.1)$ & $40(64.5)$ & 0.007 \\
DAPT & $109(75.7)$ & $69(84.1)$ & $40(64.5)$ & 0.007 \\
Beta-blockers & $120(83.3)$ & $72(87.8)$ & $48(77.4)$ & 0.098 \\
ACEIs/ARBs & $109(75.7)$ & $67(81.7)$ & $42(67.7)$ & 0.053 \\
Statins & $138(95.8)$ & $80(97.6)$ & $58(93.5)$ & 0.233 \\
\hline
\end{tabular}

ACEI Angiotensin-converting enzyme inhibitor, ARB Angiotensin-receptor blockers, NSTE-ACS Non-ST-elevation acute coronary syndrome, STEMI ST-elevation

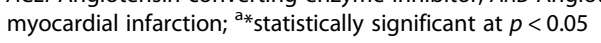


Table 4 Predictors of in-hospital mortality among ACS patients

\begin{tabular}{lll}
\hline Variables & In-hospital death $(\boldsymbol{n}=\mathbf{3 7})$ & Adjusted HR (95\%Cl) \\
\cline { 2 - 3 } & Unadjusted HR (95\%Cl) & $1.01(0.98-1.04)$ \\
\hline Age (per year) & $1.02(0.99-1.04)$ & $3.64(1.81-7.29)^{*}$ \\
Residence (rural vs Urban) & $3.34(1.70-6.54)^{*}$ & $4.23(1.28-13.81)^{*}$ \\
Symptom onset to FMC > 12h & $6.08(1.861-19.87)^{*}$ & $1.96(0.84-4.56)$ \\
STEMI vs NSTEMI (ref.) & $2.03(0.92-4.47)^{*}$ & $0.92(0.41-2.40)$ \\
LVEF < 40\% ( $\geq 40 \%$ ref.) & $2.55(1.3-4.98)^{*}$ & $0.617(0.31-1.23)$ \\
GDMT $^{2}$ & $0.43(0.22-0.84)^{*}$ & $1.31(0.51-3.39)$ \\
Atrial fibrillations & $2.14(0.88-5.21)$ & $1.01(0.39-2.61)$ \\
Acute kidney injury & $2.69(1.25-5.78)^{*}$ & $7.20(3.55-14.55)^{*}$ \\
Cardiogenic shock & $7.27(3.66-14.44)^{*}$ & $1.87(0.78-4.46)$ \\
Re-infraction & $3.47(1.55-7.76)^{*}$ & $1.41(0.57-3.50)$ \\
Hospital acquired infection & $2.45(1.11-5.38)^{*}$ &
\end{tabular}

CI Confidence interval, FMC First Medical contact, GDMT Guideline directed medical therapy, HR Hazard ratio, LVEF Left ventricular ejection fraction, STEMI STElevation Myocardial infarction. aDDMT (initiation of Dual antiplatelet, statin, beta-blockers, and ACEl within $24 \mathrm{~h}$ of hospital admission and heparin during hospital stay); ${ }^{*}$-value $<0.005$
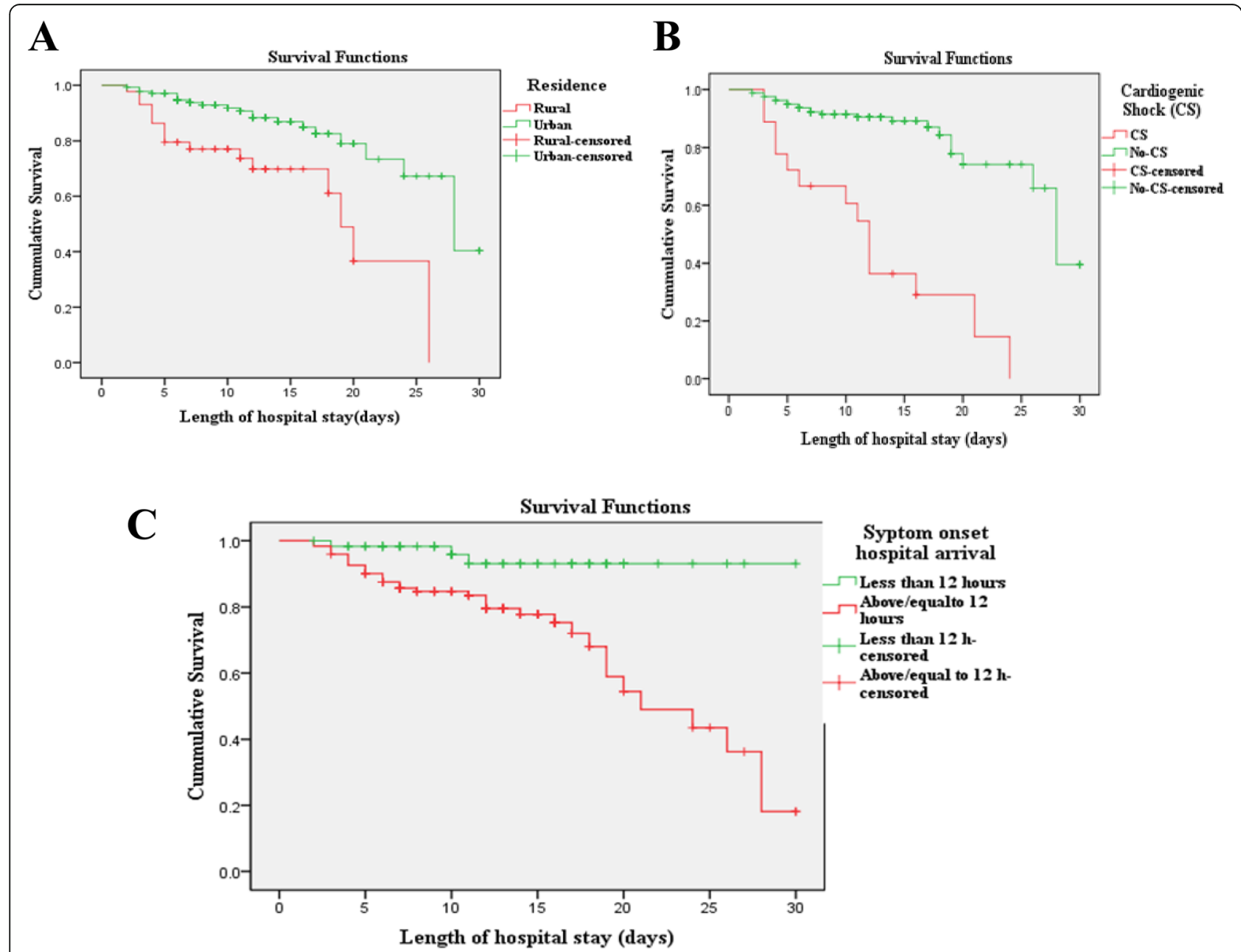

Fig. 1 Survival probability curve derived from Log rank Kaplan Meier in-hospital mortality and residence (a), cardiogenic shock (b), and symptom onset to hospital arrival (c) 
treatment protocol in our setups. There was also a significant difference in the rate of reperfusion therapy (7.2\%) observed in our study compared to prior studies from SSA such as ACCESS-south Africa where 18\% received thrombolytic and 53\% get PCI [12]. Similarly, it was lower as compared to a study conducted at Aga Khan University, Kenya study where about $68 \%$ reperfusion rate with PCI/thrombolysis [20]. This huge discrepancy in reperfusion rate was most likely due to the unavailability of thrombolytic drugs, limited modern cardiac catheterization lab with PCI, and shortage of interventional cardiologists in our country.

The all-cause in-hospital mortality rate $(20.4 \%)$ in the present study is lower compared to the study done by $\mathrm{K}$. Bogale et al. [24] in Ethiopia which reported 27\% and Desta DM et al. [25] in Ethiopia which reported 24.5\%. However, we recorded a significantly higher in-hospital mortality rate compared to ACS registries from Kenya (17.3\%) [22], South Africa (2.4\% STEMI and 1.7\% NSTE MI) [12], India (3.9\%) [19], and Middle-East countries (7.2\%) [26]. This significant discrepancy in outcome could be partly explained by differences in ACS management, particularly lack of early reperfusion therapy in our setup, prolonged prehospital delay, and high rate of non-fatal MACE observed in the present study largely contributedto this poor prognosis and higher in -hospital mortality.

The overall non-fatal MACE in the present study was $25 \%$ and without a significant difference among ACS subtypes. This finding is comparable to the ACS registry from Kenya [22] that reported a non-fatal MACE of $23 \%$. However, the rate of no-fatal MACE recorded in our study was higher compared to observational ACS studies from India [19], Bangladesh [23], and the western European countries [27]. The higher rate of nonfatal MACE among our study participants might be due to differences in risk factors, sub-optimal guidelinedirected medications, and excessive pre-hospital delay.

In the present study, rural residence, symptom onset to hospital arrival $>12 \mathrm{~h}$, and Cardiogenic shock were independent predictors of time to in-hospital mortality. In this study, ACS patients from the rural areas had a three-to-four -fold increased risk of inhospital mortality compared to those from the urban areas. Studies on ACS from developed countries also show considerable disparity when mortality is stratified by urbanization [28-30] The higher mortality rate among ACS patients from a rural area in the current study is partially explained by prolonged prehospital delay in rural residents and difference in socioeconomic status which could lead to a difference in treatment and related factors. Since more rural patients die before reaching hospitals, the actual death rate is likely to be greater than reported here.
Symptom onset to hospital arrival $>12 \mathrm{~h}$ was also an independent predictor of in-hospital mortality in the present study. This finding agrees with the previous study done by K. Bogale et al. [24] in Ethiopia which reported a significant association between delayed presentation and in-hospital mortality. Prolonged ischemic time in ACS patients has been associated with large infarct size, worse left ventricular systolic function, and more hemodynamic compromises which contribute to short-term and long-term mortality [31, 32].

Another predictor of in-hospital mortality in the present study was a cardiogenic shock. ACS patients who developed cardiogenic shock had a 7 times higher risk of in-hospital mortality rate compared to those without cardiogenic shock. Previous studies also demonstrated that cardiogenic shock is significantly associated with early mortality among ACS patients [33-35]. A study conducted by Desta DM et al. [25] in Ethiopia also reported high in-hospital mortality among ACS complicated with cardiogenic shock. Lack of reperfusion therapy and inotropic or vasopressors agent such as dobutamine and norepinephrine which are recommended by contemporary treatment guideline [36] as first-line therapy for ACS complicated with cardiogenic shock also contributed to the increased mortality rate in the current study.

\section{Key area for quality improvement}

Through this observational study, we have identified areas that need improvement to optimize the process of care and outcome among ACS patients. We observed a prolonged delay between symptom onset and presentation to hospitals for emergency care. This finding highlights the importance of creating awareness about ACS symptoms for general populations and community health workers since the prehospital delay was an independent predictor of in-hospital death in the present study. All-cause in-hospital mortality and non-fatal MACE rates in the present study were unacceptably high, stressing the importance of guideline-directed medical therapy and early reperfusion therapy. The use of guideline-directed medications such as dual antiplatelet, bet-blockers, and ACEIs should be prioritized during the acute phase (the first $24 \mathrm{~h}$ ) since it has an impact on patient prognosis. In addition, increasing the number of interventional cardiologist and PCI cable center in available tertiary care hospitals as well as linking them with general hospitals and emergency medical service might improve outcomes of patients with ACS.

\section{Strength and limitations of the study}

As a strength, the study was prospectively described relevant management protocol, in-hospital outcomes and independent predictors of in-hospital mortality 
among ACS patients. This study highlighted the process of care as quality indicators and identified area needs improvement to reduce mortality rate and complications among ACS patients in Ethiopia. However, the study has several limitations. First, this study was conducted on a small sample size (181 participants) due to erratic patient follow to selected hospitals. The calculated sample size was 190 based on the study conducted by A. Giday et al. in Ethiopia which reported an in-hospital mortality rate of $14.4 \%$ [37]. Second, the data represent patients survived the acute phase because ACS patients who died prehospital and shortly after hospital arrival were excluded. Third, we did not capture a key aspect of quality measures such as door-to-balloon/needle since only a minority of ACS patients received reperfusion therapy. Finally, we did not record economic cost, patient quality of life and post discharge medication adherence and outcomes which are also important performance measures.

\section{Conclusions}

In the present study, the use of guideline-directed inhospital medications was sub-optimal, and the rate of reperfusion therapy was very low (almost negligible). The rate of guideline-directed medications upon discharge was comparable to the practice of other countries and prior ACS registries report. The overall in-hospital mortality and non-fatal MACE rates were unacceptably high and highlight the urgent need for national qualityimprovement focusing on early initiation of evidencebased medications, reperfusion therapy, and emergency medicals service as well as methods to enhance transportation to the hospitals.

\section{Abbreviations}

ACEl: Angiotensin Converting Enzyme Inhibitors; ACS: Acute Coronary Syndromes; ARB: Angiotensin Receptor Blockers; CVD: Cardiovascular Diseases; DAPT: Dual Antiplatelet Therapy; IHD: Ischemic Heart Disease; JUMC: Jimma University Medical Center; MACE: Major Adverse cardiovascular Events; NSTE-ACS: No-ST-elevations Acute Coronary Syndromes; SPSH: Saint Peter Specialized Hospital; SSA: Sub-Saharan Africa; STEMI: ST-elevations Myocardial infarction

\section{Supplementary Information}

The online version contains supplementary material available at https://doi. org/10.1186/s12873-021-00433-3.

\section{Additional file 1}

\section{Acknowledgements}

We would like to acknowledge Jimma University for funding this study. We are also indebted to all the study participants who gave their consent to participate in this study.

\section{Authors' contributions}

KF: conceptualization, Methodology, Investigation, Analysis and Write up of the manuscript. FB and ET: Methodology, Data curation, Drafting, Interpretation and Edition of the data and Supervision. TSM, GF and LC: Methodology, supervision and edition of the manuscript. All authors critically revised the manuscript and have approved the final version of the manuscript.

\section{Funding}

This research was financially supported by Jimma University Institute of Health; grant number [JUIH/193/10]. The funding body did not have any role in study design, data collection, and data analysis, interpretation of data or in writing the manuscript.

\section{Availability of data and materials}

The dataset that was used to support the finding of this study will be made available from the corresponding author upon reasonable request.

\section{Declarations}

Consent for publications

Not applicable.

Ethics approval and consent to participate

The study protocol was approved by the Institutional Review Board (IRB) of Jimma University, Institute of Health with a reference number of IHRPGD/ 193/18. Permission was obtained from responsible bodies of respective hospitals before interviewing patients and extracting data from active patient's case records. Written and verbal informed consent was obtained from all study participants. All the study protocols were performed in accordance with the ethical principles of the Declaration of Helsinki [38]. The confidentiality and privacy of participant's data were maintained by using different codes throughout the data collection tools.

\section{Competing interests}

The authors declare that there is no competing of interest regarding this work.

\section{Author details}

${ }^{1}$ Department of Clinical Pharmacy, Institute of Health, Jimma University, P.O.Box: 378, Jimma, Oromia, Ethiopia. ${ }^{2}$ Department of Internal Medicine, Institute of Health, Jimma University, Jimma, Oromia, Ethiopia. ${ }^{3}$ Department of clinical pharmacy, Institute of Health Sciences, Wollega University, Nekemte, Oromia, Ethiopia. ${ }^{4}$ School of Pharmacy, Faculty of Medicine, The Chinese University of Hong Kong, Shatin, New territory, Hong Kong. ${ }^{5}$ Department of Pharmacology and Clinical Pharmacy, Collage of Health Science, Addis Ababa University, Addis Ababa, Ethiopia.

Received: 29 December 2020 Accepted: 18 March 2021

Published online: 31 March 2021

\section{References}

1. Roth GA, Johnson C, Abajobir A, Abd-Allah F, Abera SF, Abyu G, et al. Global, regional, and National Burden of cardiovascular diseases for 10 causes, 1990 to 2015. J Am Coll Cardiol. 2017;70(1):1-25. https://doi.org/10.1 016/j.jacc.2017.04.052.

2. Mensah GA, Wei GS, Sorlie PD, Fine LJ, Rosenberg Y, Kaufmann PG, et al. Decline in cardiovascular mortality: possible causes and implications. Circ Res. 2017;120(2):366-80. https://doi.org/10.1161/CIRCRESAHA.116.309115.

3. Ritchey MD, Wall HK, George MG, Wright JS. US trends in premature heart disease mortality over the past 50 years: where do we go from here? Trends Cardiovasc Med. 2020;30(6):364-74. https://doi.org/10.1016/j.tcm.201 9.09.005.

4. Balda-Canizares JA, Tamariz L, Moreno-Zambrano D, Pareja D, Ortiz-Prado E, Palacio A, et al. Increasing myocardial infarction mortality trends in a middle-income country. Cardiovasc Diagn Ther. 2018;8(4):493-9. https://doi. org/10.21037/cdt.2018.07.03.

5. Vedanthan R, Seligman B, Fuster V. Global perspective on acute coronary syndrome: a burden on the young and poor. Circ Res. 2014;114(12):195975. https://doi.org/10.1161/CIRCRESAHA.114.302782.

6. Yuyun MF, Sliwa K, Kengne AP, Mocumbi AO, Bukhman G. Cardiovascular diseases in sub-Saharan Africa compared to high-income countries: an epidemiological perspective. Glob Heart. 2020;15(1):15. https://doi.org/10. 5334/gh.403.

7. Hamid S, Groot W, Pavlova M. Trends in cardiovascular diseases and associated risks in sub-Saharan Africa: a review of the evidence for Ghana, 
Nigeria, South Africa, Sudan and Tanzania. Aging Male. 2019;22(3):169-76. https://doi.org/10.1080/13685538.2019.1582621.

8. Nkoke C, Luchuo EB. Coronary heart disease in sub-Saharan Africa: still rare, misdiagnosed or underdiagnosed? Cardiovasc Diagn Ther. 2016;6(1):64-6. https://doi.org/10.3978/j.issn.2223-3652.2015.08.01.

9. Kakou-Guikahue M, N'Guetta R, Anzouan-Kacou JB, Kramoh E, N'Dori R, Ba $S A$, et al. Optimizing the management of acute coronary syndromes in subSaharan Africa: a statement from the AFRICARDIO 2015 consensus team. Arch Cardiovasc Dis. 2016;109(6-7):376-83. https://doi.org/10.1016/j.acvd.2 015.12.005.

10. Medagama A, Bandara R, De Silva C, Galgomuwa MP. Management of acute coronary syndromes in a developing country; time for a paradigm shift? An observational study. BMC Cardiovasc Disord. 2015;15(1):1-8. https://doi.org/1 0.1186/s12872-015-0125-y.

11. Hertz JT, Reardon JM, Rodrigues CG, De Andrade L, Limkakeng AT, Bloomfield GS, et al. Acute myocardial infarction in sub-Saharan Africa: the need for data. PLoS One. 2014;9(5):1-7.

12. Schamroth C, Montalescot G, Antepara N, Escobar A, Alam S, Leizorovicz A et al. Management of acute coronary syndrome in South Africa: insights from the ACCES (acute coronary events - a multinational survey of current management strategies) registry. Cardiovasc J Afr. 2012;23(7):365-70. https:// doi.org/10.5830/CVJA-2012-017.

13. Giday A, Weldeyes E. Trends in cardiovascular disease over Time: a 30-year retrospective analysis of medical-ICU admissions in Addis Ababa, Ethiopia. Ethiop Med J. 2015;53(3):133-9.

14. Misganaw A, Haregu TN, Deribe K, Tessema GA, Deribew A, Melaku YA, et al. National mortality burden due to communicable, non-communicable, and other diseases in Ethiopia, 1990-2015: findings from the global burden of disease study 2015. Popul Health Metrics. 2017;15(1):1-17.

15. Leuner $\mathrm{CJ}$, Weldegerima AH. Cardiology services in Ethiopia. Eur Heart J. 2018;39(29):2699-700. https://doi.org/10.1093/eurheartj/ehy373.

16. Thygesen K, Alpert JS, Jaffe AS, Simoons ML, Chaitman BR, White HD. Third universal definition of myocardial infarction. J Am Coll Cardiol. 2012;60(16): 1581-98. https://doi.org/10.1016/j.jacc.2012.08.001.

17. O'Gara PT, Kushner FG, Ascheim DD, Casey DE, Chung MK, De Lemos JA, et al. 2013 ACCF/AHA guideline for the management of st-elevation myocardial infarction: a report of the American college of cardiology foundation/american heart association task force on practice guidelines. J Am Coll Cardiol. 2013;61(4):78-140.

18. Amsterdam EA, Wenger NK, Brindis RG, Casey DE, Ganiats TG, Holmes DR, et al. 2014 AHA/acc guideline for the management of patients with non-STelevation acute coronary syndromes: a report of the American College of Cardiology/American Heart Association task force on practice guidelines. J Am Coll Cardiol. 2014;64(24):e139-228. https://doi.org/10.1016/j.jacc.2014.09. 017.

19. Mohanan PP, Mathew R, Harikrishnan S, Krishnan MN, Zachariah G, Joseph J, et al. Presentation, management, and outcomes of 25748 acute coronary syndrome admissions in Kerala, India: results from the Kerala ACS registry. Eur Heart J. 2013:34(2):121-9. https://doi.org/10.1093/eurhearti/ehs219.

20. Shavadia J, Yonga G, Otieno H. A prospective review of acute coronary syndromes in an urban hospital in sub-Saharan Africa. Cardiovasc J Afr. 2012;23(6):318-21. https://doi.org/10.5830/CVJA-2012-002.

21. Yao H, Ekou A, Hadéou A, N'Djessan JJ, Kouamé I, N'Guetta R. Medium and long-term follow-up after ST-segment elevation myocardial infarction in a sub-Saharan Africa population: a prospective cohort study. BMC Cardiovasc Disord. 2019;19(1):1-7.

22. Bahiru E, Temu T, Gitura B, Farquhar C, Huffman MD, Bukachi F. Presentation, management and outcomes of acute coronary syndrome: a registry study from Kenyatta National Hospital in Nairobi. Kenya Cardiovasc J Afr. 2018;29(4):225-30. https://doi.org/10.5830/CVJA-2018-017.

23. Cader FA, Haq MM, Nasrin S, Kabir CS. Presentation, management practices and in-hospital outcomes of patients with acute coronary syndrome in a tertiary cardiac Centre in Bangladesh. Bangladesh Hear J. 2018;32(2):106-13. https://doi.org/10.3329/bhj.v32i2.36097.

24. Bogale K, Mekonnen D, Nedi T, Woldu MA. Treatment outcomes of patients with acute coronary syndrome admitted to Tikur Anbessa specialized hospital, Addis Ababa. Ethiopia Clin Med Insights Cardiol. 2019;13:1.

25. Desta DM, Nedi T, Hailu A, Atey TM, Tsadik AG, Asgedom SW, et al. Treatment outcome of acute coronary syndrome patients admitted to ayder comprehensive specialized hospital, mekelle, Ethiopia; a retrospective cross-sectional study. PLoS One. 2020;15(2):1-17.
26. AlHabib KF, Sulaiman K, Al-Motarreb A, Almahmeed W, Asaad N, Amin H, et al. Baseline characteristics, management practices, and long-term outcomes of middle eastern patients in the second gulf registry of acute coronary events (gulf RACE-2). Ann Saudi Med. 2012;32(1):9-18. https://doi. org/10.5144/0256-4947.2012.9.

27. André R, Bongard V, Elosua R, Kirchberger I, Farmakis D, Häkkinen U, et al. International differences in acute coronary syndrome patients' baseline characteristics, clinical management and outcomes in Western Europe: the EURHOBOP study. Heart. 2014;100(15):1201-7. https://doi.org/10.1136/hea rtjnl-2013-305196.

28. Villapiano N, Iwashyna TJ, Davis MM. Worsening rural-urban gap in hospital mortality. J Am Board Fam Med. 2017;30(6):816-23. https://doi.org/10.3122/ jabfm.2017.06.170137.

29. Cai M, Liu E, Li W. Rural versus urban patients: Benchmarking the outcomes of patients with acute myocardial infarction in Shanxi, China from 2013 to 2017. Int J Environ Res Public Health. 2018;15:9.

30. Kim HS, Kang DR, Kim I, Lee K, Jo H, Koh SB. Comparison between urban and rural mortality in patients with acute myocardial infarction: a nationwide longitudinal cohort study in South Korea. BMJ Open. 2020;10(4): 1-6.

31. Guerchicoff A, Brener SJ, Maehara A, Witzenbichler B, Fahy M, Xu K, et al. Impact of delay to reperfusion on reperfusion success, infarct size, and clinical outcomes in patients with St-segment elevation myocardial infarction: the INFUSE-AMI trial (INFUSE-anterior myocardial infarction). JACC Cardiovasc Interv. 2014;7(7):733-40. https://doi.org/10.1016/j.jcin.2014.01.166.

32. McNair PW, Bilchick KC, Keeley EC. Very late presentation in ST elevation myocardial infarction: predictors and long-term mortality. IJC Heart Vasc. 2019;22:156-9. https://doi.org/10.1016/j.ijcha.2019.02.002.

33. Holmes DR, Berger PB, Hochman JS, Granger CB, Thompson TD, Califf RM, et al. Cardiogenic shock in patients with acute ischemic syndromes with and without ST-segment elevation. Circulation. 1999;100(20):2067-73. https://doi.org/10.1161/01.CIR.100.20.2067.

34. Awad HH, Anderson FA, Gore JM, Goodman SG, Goldberg RJ. Cardiogenic shock complicating acute coronary syndromes: insights from the global registry of acute coronary events. Am Heart J. 2012;163(6):963-71. https:// doi.org/10.1016/j.ahj.2012.03.003.

35. Kasahara T, Sakakura K, Yamamoto K, Taniguchi Y, Tsukui T, Seguchi M, et al. Clinical factors associated with in-hospital mortality in patients with acute myocardial infarction who required intra-aortic balloon pumping. Int Heart J. 2020;61 (2):209-14. https://doi.org/10.1536/ihj.19-368.

36. Van Diepen S, Katz JN, Albert NM, Henry TD, Jacobs AK, Kapur NK, et al. Contemporary Management of Cardiogenic Shock: A Scientific Statement from the American Heart Association. Circulation. 2017;136:232-68.

37. Giday A, Weldeyes E, O'Mara J. Characteristics and management of patients with acute coronary syndrome at Tikur Anbessa specialized hospital, Addis Ababab. Ethiopia Ethiop Med J. 2013:51(4):269-72.

38. World Medical Association. World medical association declaration of Helsinki: ethical principles for medical research involving human subjects. JAMA. 2013;310(20):2191-4.

\section{Publisher's Note}

Springer Nature remains neutral with regard to jurisdictional claims in published maps and institutional affiliations.

Ready to submit your research? Choose BMC and benefit from:

- fast, convenient online submission

- thorough peer review by experienced researchers in your field

- rapid publication on acceptance

- support for research data, including large and complex data types

- gold Open Access which fosters wider collaboration and increased citations

- maximum visibility for your research: over $100 \mathrm{M}$ website views per year

At $\mathrm{BMC}$, research is always in progress.

Learn more biomedcentral.com/submission 